\title{
COMPARISONS OF DIFFERENTIAL WARMING RATES AND TISSUE TEMPERATURES IN SOME SPECIES OF DESERT BATS
}

\author{
J. R. HiRShFELd AND M. J. O'FARRELL \\ Department of Riological Sciences. Iniversity of Nevada. Las Vegas. Las Vegas, NV 89154. U.S.A.
}

(Received 27 Octoher 1975)

\begin{abstract}
An examination of warming rates of chest muscle in relation to rectal temperature and subsequent thermal mapping of selected tissues in active bats has shown the following trends:

1. During arousal, chest muscle warms slightly faster than rectal temperature in Pipistrellus hesperus, Antrozous pallidus, Myotis californicus, M. thysanodes. Eptesicus fuscus, and Tadarida hrasiliensis, whereas in Plecotus townsendii chest muscle warms twice as fast as rectal.

2. Bats that warmed sufficiently to initiate flight in the laboratory had interscapular temperatures that were higher than rectal, brain, or adjacent flight muscles.

3. Field data. however, indicate interscapular temperatures to be lower than flight muscle temperature, especially following periods of sustained flight.

4. Both laboratory and field data show that certain bats are capable of coordinated and sustained flight at tissue temperatures well below recognized homeothermic levels.
\end{abstract}

\section{INTRODUCTION}

Lyman \& Chatfield (1950) showed that there exists a marked differential in blood flow between the abdominal and thoracic regions in the Syrian hamster, Mesocricetus auratus waterhousi. This differential has since been shown to occur in several other nonvolant mammalian hibernators (see reviews of Lyman, 1965 and 1970) as well as for some bats (Rauch \& Hayward. 1970: Rauch, 1973; and Rauch \& Beatty, 1975). These studies showed, in general, that blood flow is chiefly confined to anterior body regions during arousal from hibernation, with the myocardium, diaphram. skeletal muscles, and brown adipose tissues receiving the highest rates of blood flow. A differential in blood flow between the abdominal and thoracic cavities accounts for a marked temperature differential between these regions.

Certain species of bats have demonstrated winter activity in temperate regions (O'Farrell \& Bradley, $1970)$ with the concomitant ability to fly at reduced body temperatures (Bradley \& O'Farrell, 1969; and Studier \& O'Farrell, 1972). Studier (1974) reported a predictive relationship between rectal temperature and flight muscle temperature in two species of bats during arousal from torpor. Since the bats of the southwestern U.S. show a high degree of variability in body temperature required for initiation and maintenance of flight, the relationship described by Studier (1974) needs further examination.

The present study is an attempt to determine the extent of thermal differences in the body of warming and active bats, in order to gain an understanding of the processes involved in low body temperature flight. In addition, the capability of low body temperature flight raises the question of the critical body temperatures at which these animals can achieve coordinated flight, particularly for the brain and flight muscles.

\section{MATERIALS AND METHODS}

Bats studied were collected at various locations in southern Nevada at elevations ranging from 600 to $2500 \mathrm{~m}$ from September, 1974, through March, 1975. The following species were examined: Pipistrellus hesperus. Antrozous pallidus, Myotis californicus, M. thysanodes, Eptesicus fuscus. Plecotus townsendii, and Tadarida hrasiliensis. Adult bats of both sexes were studied within 3 days of capture.

Bats were first cooled to approx $5-10^{\circ} \mathrm{C}$ in a refrigerator at $4^{\circ} \mathrm{C}$ ambient temperature, then restrained (Studier, 1974) and allowed to warm up at room temperatures $\left(23-27^{\circ} \mathrm{C}\right.$, except $P$. townsendii which was allowed to warm up at $14-15^{\circ} \mathrm{C}$. Simultaneous readings were taken from chest muscle and rectum, at $1 \mathrm{~min}$ intervals, using a Yellow Springs Instrument Telethermometer with YSI hypodermic thermister probe, and a quick registering Schultheis mercury thermometer, respectively, similar to that of Studier (1974). The hypodermic probe was carefully inserted into the left pectoral muscle mass and the Schultheis thermometer was inserted $8 \mathrm{~mm}$ into the rectum. Bats were flown, using the method of Bradley \& O'Farrell (1969) when they reached an arbitrary known flight temperature (Studier \& O'Farrell, 1972), and interscapular, flight muscle, and brain temperature were recorded and compared with rectal temperature immediately after initiation of flight. Brain temperatures were obtained by inserting the hypodermic thermistor through the external auditory meatus into the central brain region. In most instances, several warming trials were obtained on individual bats before brain and tissue temperatures were taken.

In September, while bats were being netted over a water hole, rectal, chest muscle, and interscapular temperatures were determined within $1 \mathrm{~min}$ of capture, using similar methods to those performed in the laboratory.

\section{RFSUYTS}

Chest muscle temperatures $\left(T_{\mathrm{c}}\right)$ and rectal temperatures $\left(T_{\mathrm{r}}\right)$ showed a high degree of correlation in arousing bats (Figs. $1 \& 2$ ). Several distinct patterns can be seen among those bats capable of low body 


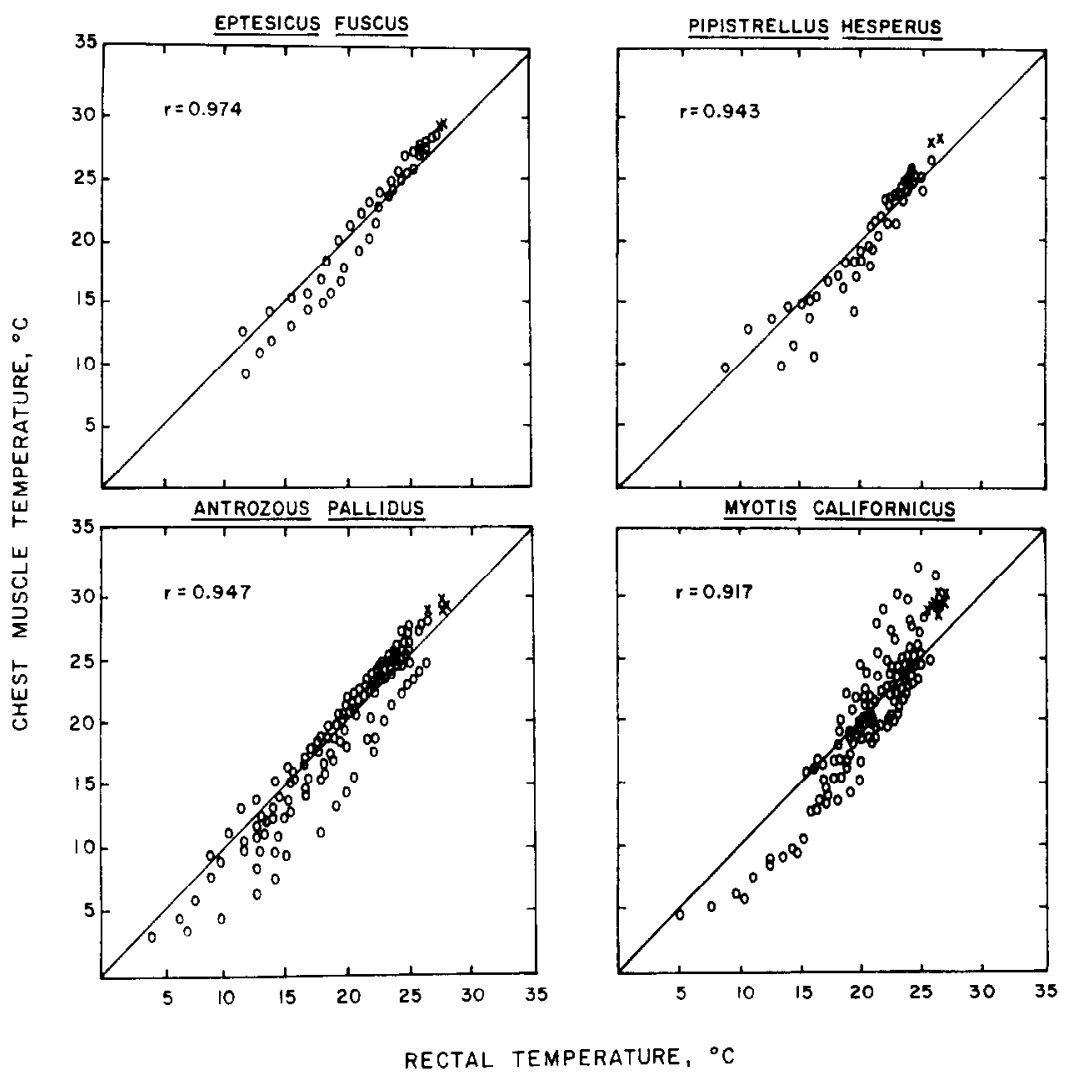

Fig. 1. Chest muscle temperature $\left(T_{c}\right)$ and rectal temperature $\left(T_{r}\right)$ during arousal in Eptesicus fuscus, Antrozous pallidus, Pipistrellus hesperus, and Myotis californicus. The solid diagonal line represents a reference line where $T_{\mathrm{c}}=T_{1} . \mathrm{X}=$ point at which bats could initiate flight.

temperature flight. The most similar patterns are shown in Fig. 1. With few exceptions, $T_{i}$ was lower than $T_{r}$ at the lower temperatures. The point or range of temperatures where $T_{c}$ was equal to or higher than $T_{\mathrm{r}}$ varied by species. In $A$. pallidus, it was noted that as the animals were stressed by water and food deprivation, $T_{c}$ remained lower than $T_{\mathrm{r}}$ (Fig. 1).

The 3 species presented in Fig. 2 show warming patterns which differ from the previous species. Although $P$. townsendii and $M$. thysanodes are also low body temperature fliers, T. brasiliensis is a high body temperature flier (Studier \& O'Farrell, 1972). In $M$. thisanodes, $T$ is higher than $T$, throughout the warming except for a point around $20 \mathrm{C}$ at which time $T_{c}=T_{\mathrm{r}}$. Plecotus townsendii shifts from a lower $T_{c}$ to a higher relationship very easily in warming. The pattern exhibited by $T$. brasiliensis is most similar to $M$. californicus; however, $T_{s}$ does not exceed $T_{\mathrm{r}}$ until $27 \mathrm{C}$. It should be noted that for all bats tested. the temperature at which $T_{\mathrm{c}}$ equalled or exceeded $T_{\mathrm{r}}$ corresponded to the time when the bats began vocalizing and wriggling.

Regression analysis of $T_{\mathrm{c}}$ on $T_{\mathrm{r}}$ for warming bats points out further differences among the species (Table 1). The most striking difference is the significantly greater slope for $P$. townsendii. All analyses showed a high degree of predictability $\left(r^{2}>0.84\right)$.

Warming rates of $T_{r}$ did not differ significantly among any of the species tested either while restrained or after flight was initiated exeept for $A$. pallidus $(P<0.05$; Table 2). Similar patterns also were observed in warming rates of $T_{\varepsilon}$. Although warming rates of $T_{c}$ tended to be greater than $T_{\mathrm{r}}$, these rates were not significantly greater except for $P$. townsendii $(P<0.05)$.

A comparison of selected tissue temperatures following flight which was initiated in the laboratory is given in Table $3 . T_{r}$ was significantly lower than all other tissues tested $(P<0.01)$. Brain. chest muscle. and interscapular temperatures did not differ significantly, although interscapular temperatures tended to be higher in most instances. Although $P$. townsendii initiated flight at a greatly reduced $T_{\mathbf{r}}$, tissue temperatures did not differ from any other bats tested. Tissue temperatures obtained in the field were similar to those given in Table 3.

\section{DISCUSSION}

In hibernators, an antcropostcrior tcmpcraturc gradient occurs during arousal with thoracic being greater than abdominal temperatures (see review in Lyman, 1965). Study of this gradient in relation to changes in blood flow in hibernating bats have been described in detail (Rauch \& Hayward, 1970; Rauch, 1973; and Rauch \& Beatty, 1975). To summarizc these findings, it was found that during arousal. capillary blood flow to brown fat and to anterior musclc is significantly greater than hibernating flow rates. Distribution of blood in liver, kidneys, and gastrointestinal tissues were greatly reduced during arousal. After arousal has occurred, blood distribution in the various regions of the body was similar to that of nonarousing. hibernating bats. Studier (1974) de- 
scribed temperature differentials in bats which supports the occurrence of an anteroposterior temperature gradient. Chest muscle and rectal temperature differentials in Figs. $1 \& 2$ also show an anteroposterior gradient. In several of the species. however. rectal temperatures remain higher than chest muscle temperatures for a period longer than expected from the results of Rauch (1973). This may be due, in part, to the overall physiological condition of our experimental animals. As was described earlier. we found that with increasing stress, chest muscle temperature tended to remain lower than rectal temperature. Differences may also be due to the fact that the bats tested were either non-hibernators (T. brasiliensis) or known low body temperature fliers.

The points at which chest muscle temperature equalled or exceeded rectal temperature may be the time at which visceral vasodilation occurs. These points coincide within the range of body temperatures at which these bats are known to be able to initiate

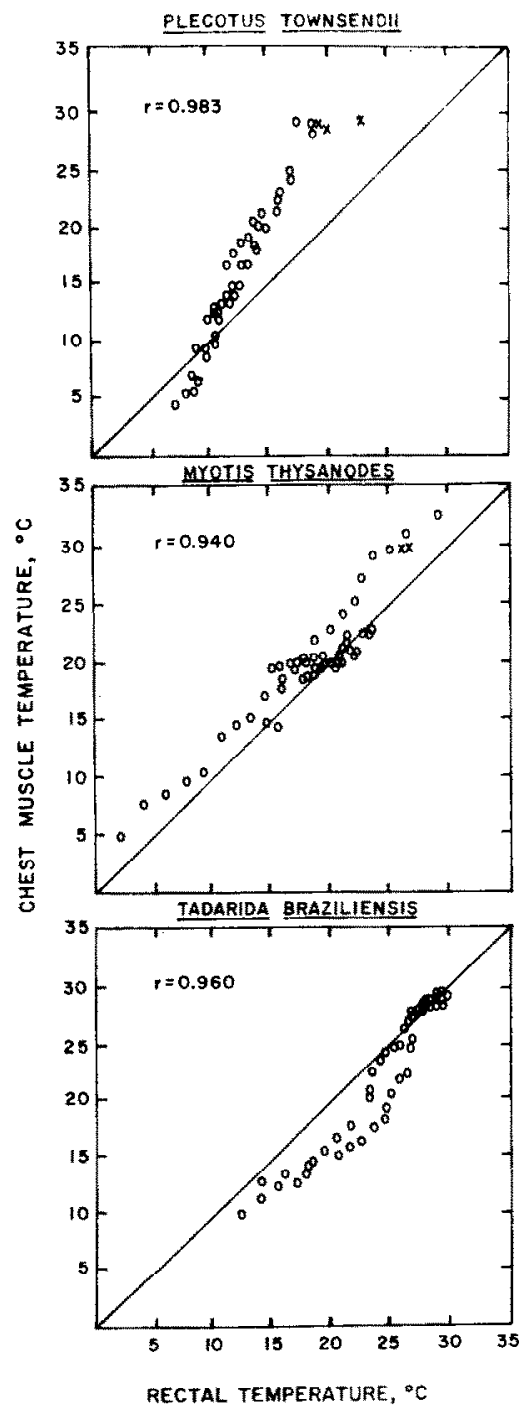

Fig. 2. Chest muscle temperature $\left(T_{6}\right)$ and rectal temperature $\left(T_{r}\right)$ during arousal in Plecotus townsendii. Myotis thsanodes, and Tadarida brasiliensis. The solid diagonal line represents a reference line where $T_{c}=T_{\mathrm{r}} . \mathrm{X}=$ point at which bats could initiate flight. and maintain flight at reduced ambient temperatures. The warming trends we observed are somewhat different than those given by Rauch (1973). which is probably a reflection of the ambient temperature during testing. The pattern exhibited by $P$. townsendii does conform to that of Rauch (1973), and they were tested at low ambient temperatures. It would have been preferable to conduct all tests under these conditions. Our facilities precluded the opportunity to conduct the tests at a constant, low ambient temperature.

The results obtained using the low body temperature flicr. M. sodalis. by Studier (1974) were comparable to our results (Table 1). On the other hand. $E$. fuscus had a significantly higher slope $(P<0.01)$. Eptesicus in southern Nevada are capable of activity at low hody temperatures. It appears that the desert variety is more physiologically labile than eastern or northern E. fuscus. It is also possible that there was a difference in physiological condition of the two varieties. due to differences in seasons that the animals were tested.

Warming rates of laboratory tested animals (Table 2) are comparable to rectal warming rates determined in hibernacula (Twente, 1955: and Hughes. 1968). Twente (1955) described a linear warming trend. whereas Hughes (1968) found a logarithmic increase in rectal temperature. We found both trends in the bats listed. Laboratory and field rates were similar. Variations we observed were attributable to stress and declining physiological condition which may account for differences found in the previous studies.

The differential in tissue temperatures (Table 3 ) are as expected in light of differential blood flow. Interscapular temperatures should be slightly higher since these bats were in the process of arousal when flight was initiated. It is possible that for low body temperature flicrs, high interscapular temperatures may be maintained during flight at low ambient temperatures. If so. this would be advantageous in maintaining the thermal gradicnt between deep corc and ambient temperatures. The low brain and chest muscle temperatures, however, are surprising for an activity that is associated with at high homeothermic capacity. Detailed studies on the pre-optic anterior hypothalamus $(\mathrm{PO} / \mathrm{AH})$ in E. fuscus aid in understanding the low brain temperatures obtained in the present study (Kluger \& Heath, 1971a, b, and c). Lesions placed in the $\mathrm{PO} / \mathrm{AH}$ resulted in only minor losses of thermoregulatory ability. It was determined that the $\mathrm{PO} / \mathrm{AH}$ of $E$. firscus was less thermally sensitive than that of other vertebrates and that other central nervous structures may have acquired increased thermor* egulatory function. Finally, it was suggested that as an open-mouthed fler, $\mathrm{PO} / \mathrm{AH}$ fluctuates in temperature during thight which possibly preadapts $E$. fuscus for heterothermy.

This information is valuable when considering low body temperature flight. Many bats in the southwestern United States are active throughout the winter months (O'Farrell \& Bradley, 1970) and are capable of low body temperature flight. directly dependent on ambient temperatures (O'Farrell \& Bradley, 1975). The low tissue temperatures obtained in post-flight bats (Table 3) indicate that these animals are capable of sustained, coordinated activity at greatly reduced body temperatures. A less thermally sensitive $\mathrm{PO} / \mathrm{AH}$ 
Table 1. Regression analysis of chest muscle temperature on rectal temperature of several species of bats. One standard error is given in parentheses. $N=$ the number of actual temperatures obtained at $1 \mathrm{~min}$ intervals

\begin{tabular}{|c|c|c|c|c|}
\hline Species & N & Equation & $r^{2}$ & Source \\
\hline Pipistrellus hesperus & 48 & $\begin{aligned} & T_{c}= 1.102 \\
&(0.058)^{\top}-2.422\end{aligned}$ & 0.889 & Present study \\
\hline Antrozous pallidus & 119 & $\begin{aligned} T_{C}= & \left.1.159{ }^{\top}{ }^{\top}-3.036\right)^{r}-3.551\end{aligned}$ & 0.897 & Present study \\
\hline Myotis californicus & 127 & $T_{c}=1.3199 T^{T} r-6.638$ & 0.840 & Present study \\
\hline Myotis thysanodes & 53 & $T_{c}=\frac{0.959}{(0.049)^{\top} r}+2.335$ & 0.883 & Present study \\
\hline Myotis sodalls & 45 & $\begin{array}{c}T_{c}=\frac{1.196}{(0.052)} r-1.666 \\
\end{array}$ & - & (studier, 1974) \\
\hline Eptesicus fuscus & 40 & $T_{c}=\frac{1.224}{(0.046)} \mathrm{T} r-4.633$ & 0.949 & Present study \\
\hline Eptesicus fuscus & 80 & $T_{c}=1.049 T^{T} T^{2}+0.757$ & - & (Studier, 1974) \\
\hline Plecotus townsendii & 41 & $T_{c}=\frac{2.208}{(0.066)} T^{r}-11.669$ & 0.966 & Present study \\
\hline Tadarida brasiliensis & 51 & $T_{c}=\frac{1.252}{(0.052)} \mathrm{r}-8.063$ & 0.922 & Present study \\
\hline
\end{tabular}

Table 2. Mean warming rates $\left({ }^{\circ} \mathrm{C} / \mathrm{min}\right)$ of several species of desert bats. One standirrd error is given in parentheses. $N=$ number of warming trials. Usually more than 1 warming trial wats obtained for each individual

\begin{tabular}{|c|c|c|c|c|}
\hline Spectes & N & $T_{r}$ & $T_{c}$ & Activity \\
\hline Pipistrellus hesperus & $\begin{array}{l}3 \\
3\end{array}$ & $\begin{array}{c}0.83 \\
(0.22) \\
0.76 \\
(0.40)\end{array}$ & $\begin{array}{l}1.05 \\
(0.30) \\
0.95 \\
(0.72)\end{array}$ & $\begin{array}{l}\text { Restrained } \\
\text { After flight }\end{array}$ \\
\hline Antrozous pallidus & $\begin{array}{l}5 \\
4\end{array}$ & $\begin{array}{l}0.84 \\
(0.10) \\
0.33 \\
(0.11)\end{array}$ & $\begin{array}{l}1.00 \\
(0.09) \\
0.32 \\
(0.10)\end{array}$ & $\begin{array}{l}\text { Restrained } \\
\text { After flight }\end{array}$ \\
\hline Myotis californicus & $\begin{array}{r}10 \\
5\end{array}$ & $\begin{array}{l}1.03 \\
(0.10) \\
0.63 \\
(0.25)\end{array}$ & $\begin{array}{l}1.29 \\
(0.16) \\
1.17 \\
(0.28)\end{array}$ & $\begin{array}{l}\text { Restrained } \\
\text { After flight }\end{array}$ \\
\hline Myot is thysanodes & $\begin{array}{l}3 \\
2\end{array}$ & $\begin{array}{c}0.84 \\
(0.16) \\
0.26 \\
--\end{array}$ & $\begin{array}{c}0.91 \\
(0.26) \\
0.42 \\
-.\end{array}$ & $\begin{array}{l}\text { Restrained } \\
\text { After flight }\end{array}$ \\
\hline Eptesicus fuscus & $\begin{array}{l}3 \\
2\end{array}$ & $\begin{array}{c}0.81 \\
(0.13) \\
0.27 \\
-.-\end{array}$ & $\begin{array}{c}0.93 \\
(0.75) \\
0.30 \\
--\end{array}$ & $\begin{array}{l}\text { Restrained } \\
\text { After flight }\end{array}$ \\
\hline Plecotus townsendiy & $\begin{array}{l}3 \\
3\end{array}$ & $\begin{array}{l}0.69 \\
(0.07) \\
1.30 \\
(0.51)\end{array}$ & $\begin{array}{l}1.52 \\
(0.32) \\
0.44 \\
(0.69)\end{array}$ & $\begin{array}{l}\text { Restrained } \\
\text { After flight }\end{array}$ \\
\hline Tadarida brastliensis & 3 & $\begin{array}{c}0.68 \\
(0.15)\end{array}$ & $\begin{array}{c}0.73 \\
(0.15)\end{array}$ & Restrained \\
\hline
\end{tabular}

Table 3. Mean tissue temperatures $(\mathrm{C})$ of several species of desert bats following initial flight. One standard error is given in parentheses. $N=$ number of individual bats examined: $T_{1}=$ rectal temperature; $T_{\mathrm{b}}=$ brain temperature; $T_{\mathrm{i}}=$ interscapular temperature; $T_{\mathrm{c}}=$ chest muscle temperature

\begin{tabular}{|c|c|c|c|c|c|}
\hline Species & N & $T_{r}$ & $T_{b}$ & $T_{i}$ & ${ }^{\top}{ }_{C}$ \\
\hline Pipistrellus hesperus & 3 & $\begin{array}{l}26.50 \\
(0.81)\end{array}$ & $\begin{array}{l}30.45 \\
(0.56)\end{array}$ & $\begin{array}{l}31.50 \\
(0.47)\end{array}$ & $\begin{array}{l}30.03 \\
(1.54)\end{array}$ \\
\hline Antrozous pallidus & 4 & $\begin{array}{l}27.47 \\
(0.13)\end{array}$ & $\begin{array}{l}29.17 \\
(0.24)\end{array}$ & $\begin{array}{l}29.57 \\
(0.57)\end{array}$ & $\begin{array}{l}29.20 \\
(0.23)\end{array}$ \\
\hline Myotis californicus & 11 & $\begin{array}{l}25.64 \\
(0.60)\end{array}$ & $\begin{array}{l}28.81 \\
(0.58)\end{array}$ & $\begin{array}{l}29.62 \\
(0.34)\end{array}$ & $\begin{array}{l}29.10 \\
(0.44)\end{array}$ \\
\hline Myotis thysanodes & 1 & $\begin{array}{l}24.90 \\
--\end{array}$ & $\because-$ & $\begin{array}{c}28.90 \\
--\end{array}$ & 27.30 \\
\hline Eptesicus fuscus & 2 & 27.90 & $\begin{array}{c}29.60 \\
=-\end{array}$ & $\begin{array}{c}30.10 \\
. .\end{array}$ & $\begin{array}{c}29.60 \\
--\end{array}$ \\
\hline Plecotus townsendif & 3 & $\begin{array}{l}20.73 \\
(2.31)\end{array}$ & $\begin{array}{l}28.33 \\
(0.44)\end{array}$ & $\begin{array}{l}29.52 \\
(0.09)\end{array}$ & $\begin{array}{l}28.83 \\
(0.35)\end{array}$ \\
\hline
\end{tabular}


would be of adaptive value in a condition where it would not be energetically feasible for an animal to maintain a steep gradient between ambient and body temperature. It would not be necessary nor desirable to have an alternative primary thermal sensor as proposed by Kluger \& Heath (1971b). We suggest that for low body temperature fliers, a primary thermal sensor with a "coarse" sensitivity would allow for maintenance of flight at reduced temperatures and function as an energy conserving mechanism. Further studies are needed to clarify the metabolic and neuromechanisms of the flight musculature which enables these bats to fly at unusually low ambient temperalures.

Acknowledgements-We wish to thank Drs. Rauch. Kluger, and Studier for their critical reviews of this manuscript, and Dr. Bradley for his material assistance.

\section{REFERENCES}

Bradley W. G. \& O'Farrell M. J. (1969) Temperature relationships of the western pipistrelle (Pipistrellus hesperus). In Physiological systems in semi-arid environments (Edited by Hoff C. C. \& Riedesel M. L.) pp. 85-96. University of New Mexico Press, Albuquerque.

Hughes S. E. (1968) Temperature of the bat, Plecotus townsendii, during arousal. J. Mammal. 49. 140-142.

Kluger M. J. \& Heath J. E. (1971a) The effect of preopticanterior hypothalamic lesions on thermoregulation in the bat. Am. J. Physiol. 221. 144-149.

Kluger M. J. \& Heath J. E. (1971b) Thermoregulatory responses to preoptic-anterior hypothalamic heating and cooling in the bat Eptesicus fuscus. Z. vergl. Physiol. 74, $340-352$
KLUGer M. J. \& Heath J. E (1971c) Fluctuations in the preoptic-anterior hypothalamic temperature in the bat. Eptesicus fuscus. Comp. Biochem. Phvsiol. 40A. 809-813.

Lyman C. P. \& Chatfield P. O. (1950) Mechanisms of arousal in the hibernating hamster. J. exp. Zool. 114. $491-516$.

LrMan C. P. (1965) Circulation of mammalian hibernation. In Handhook of Physiology: Sect. 2. Circulation. (Edited by Hamilton W. F. \& Dow P.) pp. 1967-1990. Am. Physiol. Soc. Waverly Press. Baltimore.

LymAN C. P. (1970) Thermoregulation and metabolism in bats. In Biology of Bats. Vol. 1. (Edited by WimsatT W. A.I pp. 301-327. Academic Press, New York.

O'Farrell M. J. \& Bradley W. G. (1970) Activity patterns of bats over a desert spring. J. Mammal. 51, 18-26.

O'Farrell M. J. \& Bradley W. G. (1975) Comparative thermal relationships of flight for some bats in the southwestern United States. (In preparation).

Ralch J. C. \& Hayward J. S. (1970) Regional distribution of blood flow in the bat (Myotis lucifugus) during arousal from hibernation. Can. J. Physiol. Pharmacol. 48. 269-273

RAUCH J. C. (1973) Sequential changes in regional distribution of blood in Eptesicus fuscus (big brown bat) during arousal from hibernation. Can. J. Zool. 51. 973-981.

Rauch J. C. \& Beatty D. D. (1975) Comparison of regional blood distribution in Eptesicus fuscus (big brown bat) during torpor (summer), hibernation (winter), and arousal. Can. J. Zool. 53. 207-214.

Studier E. H. \& O'Farrell M. J. (1972) Biology of $M$ yotis thysanodes and $M$. lucifugus (Chiroptera: Vespertilionidae)-- I. Comp. Biochem. Physiol. 41A. 567-595.

Studifr E. H. (1974) Differential in rectal and chest muscle temperature during arousal in Eptesicus fuscus and $M$ votis sodalis (Chiroptera: Vespertilionidae). Comp. Biochem. Physiol. 47A. 799-802.

TWENTE J. W. JR. (1955) Some aspects of habitat selection and other behavior of cavern-dwelling bats. Ecology: 36, 706-732. 